\title{
Aligning Practice, Policy and Education with Evidence in Complementary and Alternative Medicine
}

\author{
Abraham Rudnick* \\ Department of Psychiatry and School of Occupational Therapy, Dalhousie University, Canada
}

*Corresponding author: Abraham Rudnick, Department of Psychiatry and School of Occupational Therapy, Dalhousie University, Canada.

\section{Perspective}

Complementary and Alternative Medicine (CAM) is commonly used Harris PE, et al [1], but its outcomes are mixed. For example, some prevention remedies such as Echinacea for secondary prevention of common colds have not been shown to be effective [2]. And some treatment interventions such as actual (compared to simulation) acupuncture for alleviation of some types of chronic pain have been shown to be effective [3,4]. The endorsement of CAM as such - by practicing clinicians and others supporting health care such as policy makers and health educators - when it is not rigorously shown to be more effective than placebo or sham/ simulation care, is arguably unethical, as has been demonstrated to be the case with orthomolecular psychiatry [5]. Such endorsement of CAM should thus be addressed from a practice, policy and education perspective.

From a practice perspective, no CAM should be provided (nor offered) by clinicians if there is no robust evidence supporting its effectiveness (and safety) compared to one or more effective (and safe) active interventions. Such independently replicated evidence requires multiple randomized controlled trials and metaanalysis or comparable research such as well-matched quasiexperimental studies and systematic reviewing. From a policy perspective, no CAM should be publicly funded if there is no robust evidence supporting its effectiveness (and safety); robust evidence supporting cost-effectiveness of CAM should be a preference rather than a requirement, as in various clinical situations, such as life threatening health challenges, cost considerations can be viewed as having secondary or marginal importance. And from an education perspective, no CAM should be taught to clinicians (nor arguably messaged to the general public) if there is no robust evidence supporting its effectiveness (and safety). Thus, aligning practice, policy and education with (robust) evidence is crucial for the ethics of CAM.

\section{Acknowledgement}

None.

\section{Conflict of Interest}

No conflict of interest.

\section{References}

1. Harris PE, Cooper KL, Relton C, Thomas KJ (2012) Prevalence of complementary and alternative medicine (CAM) use by the general population: a systematic review and update. Int J Clin Pract 66 (10): 924-939.

2. Karsch-Völk M, Barrett B, Kiefer D, Bauer R, Ardjomand-Woelkart K, et al. (2014) Echinacea for preventing and treating the common cold. Cochrane Database Syst Rev (2): CD000530.

3. Linde K, Allais G, Brinkhaus B, Manheimer E, Vickers A, et al. (2009) Acupuncture for tension-type headache. Cochrane Database of Syst Rev (1): CD007587.

4. Manheimer E, Cheng K, Linde K, Lao L, Yoo J, et al. (2010) Acupuncture for peripheral joint osteoarthritis. Cochrane Database of Syst Rev (1): CD001977.

5. Rudnick A (2010) Some philosophical reflections on orthomolecular psychiatry. Journal of Orthomolecular Medicine 25(2): 52-55. 